\title{
Characterization of sewage sludge ash and its effect on moisture physics of mortar
}

Krejcirikova, Barbora; Ottosen, Lisbeth M.; Kirkelund, Gunvor Marie; Rode, Carsten; Peuhkuri, Ruut Hannele

Published in:

Journal of Building Engineering

Link to article, DOI:

10.1016/j.jobe.2018.10.021

Publication date:

2019

Document Version

Peer reviewed version

Link back to DTU Orbit

Citation (APA):

Krejcirikova, B., Ottosen, L. M., Kirkelund, G. M., Rode, C., \& Peuhkuri, R. H. (2019). Characterization of sewage sludge ash and its effect on moisture physics of mortar. Journal of Building Engineering , 21, 396-403. https://doi.org/10.1016/j.jobe.2018.10.021

\section{General rights}

Copyright and moral rights for the publications made accessible in the public portal are retained by the authors and/or other copyright owners and it is a condition of accessing publications that users recognise and abide by the legal requirements associated with these rights.

- Users may download and print one copy of any publication from the public portal for the purpose of private study or research.

- You may not further distribute the material or use it for any profit-making activity or commercial gain

- You may freely distribute the URL identifying the publication in the public portal 


\section{Author's Accepted Manuscript}

Characterization of sewage sludge ash and its effect on moisture physics of mortar

Barbora Krejcirikova, Lisbeth M. Ottosen, Gunvor M. Kirkelund, Carsten Rode, Ruut Peuhkuri

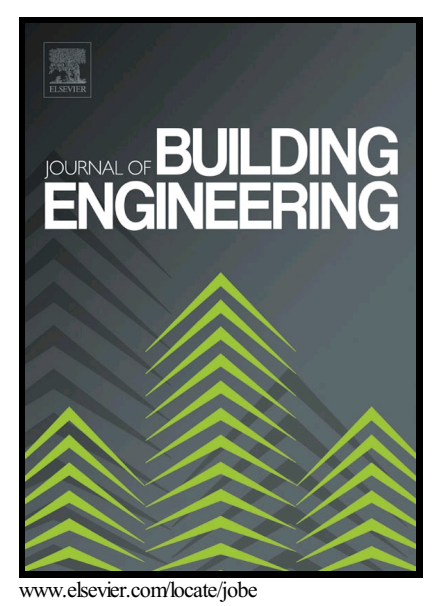

PII: $\quad$ S2352-7102(18)30615-6

DOI: $\quad$ https://doi.org/10.1016/j.jobe.2018.10.021

Reference: JOBE616

To appear in: Journal of Building Engineering

Received date: 28 May 2018

Revised date: 25 October 2018

Accepted date: 25 October 2018

Cite this article as: Barbora Krejcirikova, Lisbeth M. Ottosen, Gunvor M. Kirkelund, Carsten Rode and Ruut Peuhkuri, Characterization of sewage sludge ash and its effect on moisture physics of mortar, Journal of Building Engineering, https://doi.org/10.1016/j.jobe.2018.10.021

This is a PDF file of an unedited manuscript that has been accepted for publication. As a service to our customers we are providing this early version of the manuscript. The manuscript will undergo copyediting, typesetting, and review of the resulting galley proof before it is published in its final citable form. Please note that during the production process errors may be discovered which could affect the content, and all legal disclaimers that apply to the journal pertain. 


\title{
Characterization of sewage sludge ash and its effect on moisture physics of mortar
}

\author{
Authors: $\quad$ Barbora Krejcirikova ${ }^{1}$, Lisbeth M. Ottosen ${ }^{1}$, Gunvor M. Kirkelund ${ }^{1}$, \\ Carsten Rode ${ }^{1}$ and Ruut Peuhkuri ${ }^{2}$
}

\author{
Affiliations: \\ ${ }^{1}$ Department of Civil Engineering, Technical University of Denmark (DTU), 2800 Kgs. \\ Lyngby, Denmark, \\ ${ }^{2}$ Danish Building Research Institute, Aalborg University, 2450 Copenhagen SV, \\ Denmark
}

Corresponding author info (for published paper): Ruut Peuhkuri, Danish Building Research Institute, Aalborg University, A. C. Meyers Vænge 15, 2450 Copenhagen SV, Denmark,E-mail: rup@sbi.aau.dk

\begin{abstract}
A study was carried out to investigate the potential use of ash obtained as an incinerated by-product in sewage sludge treatment, as a possible supplementary cementitious material. Chemical parameters and granulometry of the sewage sludge ash and selected physical and hygroscopic properties of cement-ash-based mortar are presented and compared with results from previous studies. The effect of different ratios of cement substitution and two pre-treatment methods for ash, i.e. ash grinding and water washing, on the physical properties of mortar were investigated by using density, porosity and compressive strength as elemental indicators of the mortar quality. The hygroscopic sorption properties of the individual constituents alone and the resulting mortar samples were described by sorption isotherms for water vapour and by a capillary water absorption test. Results showed that the SSAs typically consisted of larger particles compared to the cement particles. Incorporation of ash resulted in more porous mortar structures compared to cement-based mortar, which affected the material's mechanical properties such as the compressive strength. 28-day compressive strength decreased with increasing ash content and porosity. Cement conveyed the greatest ability to adsorb and react with water and there were clear differences between the different ashes. Despite the differences in sorption properties between the different constituents, the effect of ash content on mortar sorption isotherms was negligible.
\end{abstract}


Keywords: Sewage sludge ash, Supplementary cementitious material (SCM), Grain size distribution, Compressive strength, Sorptivity

\section{Introduction}

Cement production is among the largest contributors to $\mathrm{CO}_{2}$-emission caused by human activity. About $5-7 \%$ of global $\mathrm{CO}_{2}$ emissions are from cement plants, and $900 \mathrm{~kg} \mathrm{CO}_{2}$ are emitted to the atmosphere during the production of one metric ton of cement (Benhelal et al., 2013). Cement is mostly used as a binder in concrete. The $\mathrm{CO}_{2}$ emission related to the making of concrete, including cement production, is between 0.1 and 0.2 ton per ton of produced concrete (Glavind and Munch-Petersen, 2000). With an annual global concrete production of approximately 3.8 billion cubic meters, concrete is the second most consumed material in the world, after water (Sedgwick, 1991). Even if only a small percentage of the overall use of cement could be substituted by alternative hydraulic binders, it would have a huge positive effect on the environmental impact of concrete production. With the vast use of Portland cement, concrete production has a significant carbon-footprint and currently represents $5 \%$ of the total global energy use in industry (Worrell et al., 2001).

The use of industrial by-products (waste material) as alternatives to cement in concrete production reduces the need for landfilling and related costs, and will consequently reduce the need to mine virgin raw materials. When secondary resources are used as partial replacements for cement, the generic term used for these products is "Supplementary Cementitious Material" (SCM) (Snellings et al., 2012). The main SCMs include coal fly ash, ground granulated blast furnace slag, silica fume, volcanic ash and metakaolin. Since the 1990s, fly ash from coal combustion processes has widely been used as an SCM. However, many countries are starting to use other raw sources of energy that are more sustainable than coal (Connolly, 2015; Lambert, 2016; Vaughan, 2016). This means that there is increased interest in identifying other ashes that can be used as an SCM, instead of fly ash from coal.

Alternatives to cement should be based on a high abundance of raw material, low carbon emission, low energy consumption, low pollutant load and possible use of waste products. Clean production, use of recycled products, and cement substitution are three effective approaches for the sustainable development of the concrete industry (Shen et al., 2017). One type of fly ash, which has shown potential as an SCM is Sewage Sludge Ash (SSA) (Chen et al., 2006, 2013; Donatello and Cheeseman, 2013; Lynn et al., 2015; Monzó et al., 1996, 2003; Yusuf et al., 2012).

Sewage sludge is a by-product formed during wastewater treatment. Approximately $10 \mathrm{Mt} /$ year of dry mass sewage sludge is produced in European countries. However, incineration can reduce this amount by $70 \%$ by mass, and $90 \%$ by volume ("Eurostat Tables, Graphs and Maps Interface (TGM) table," 2015). Sewage sludge has been widely 
used in agriculture as a fertilizer because of its content of phosphorus. However, in recent years the tendency has been to incinerate it. In the incineration process, the organic matter is combusted while by-products such as $\mathrm{CO}_{2}$, trace gases and water vapour are produced. Also, that the process of waste disposal is not completed by incineration as the SSA contains a remarkable amount of residual unburnt material. It is estimated that the global production of SSA is approximately 1.7 million tons annually, mainly from the USA, the EU and Japan, and it is expected to increase (Cyr et al., 2007; Murakami et al., 2009). A vast amount of SSA is currently being landfilled. Most SSAs are classified as waste, but it could also be regarded as a resource. Previous research has shown different options for the use of SSA in different construction materials: mortar, concrete, fired clay brick or lightweight foam materials (Ahmaruzzaman, 2010, 2010; Chen et al., 2013; Halliday et al., 2012; Kute and Deodhar, 2003; Lin et al., 2005; Lynn et al., 2015; Monzó et al., 1996, 2003; Smol et al., 2015; Wang et al., 2005 ; Wiebusch and Seyfried, 1997; Yusuf et al., 2012). Many of the applications simply use SSA as a direct substitute for raw materials such as clay or sand. However, most of these studies focused on the possibility of using SSA as an SCM in blended cement, due to the considerable environmental benefits that would be achieved.

There have been studies of several different aspects of the use of SSA as an SCM. A recent systematic review by Lynn et al. (2015) covered selected physical and chemical characteristics of SSA and its use. The present paper adds to this knowledge by reporting the properties of both SSA itself and of hardened mortar containing SSA in terms of how they affect material moisture physics, including their water vapour sorption and capillary water uptake. The aim is to raise broader perspective on SSA used in mortar, its characterization (e.g. chemical composition, grains size distribution) and to relate the effect of SSA content on actual modifications in mortar structure and performance.

2. Materials and methods

2.1 Origin of the incinerated sewage sludge ashes

SSAs from the two major Danish mono-incineration plants were used. The sludge incinerated at both plants originated from municipal wastewater treatment. The SSAs were from Avedøre Wastewater treatment plant (AVE) and from Lynettefællesskabet (LYN) (Figure $1 \mathrm{a}$ ) and b) respectively). Both plants are located in Denmark, close to the capital Copenhagen. The two plants treat the wastewater coming from 17 municipalities with approximately 1375000 inhabitants In both plants the sludge came from the primary settling tank and the secondary clarifier, was dewatered (only in Lynetten) by centrifuges before digestion. The digested sludge was dewatered by centrifuges and predried before incineration in the fluidized bed combustor. In both waste water facilities, iron was used to precipitate phosphorus, and the sewage sludge was incinerated in a 
fluidized bed combustor at about $850^{\circ} \mathrm{C}$. After sampling, the ashes were stored in closed plastic containers at room temperature.
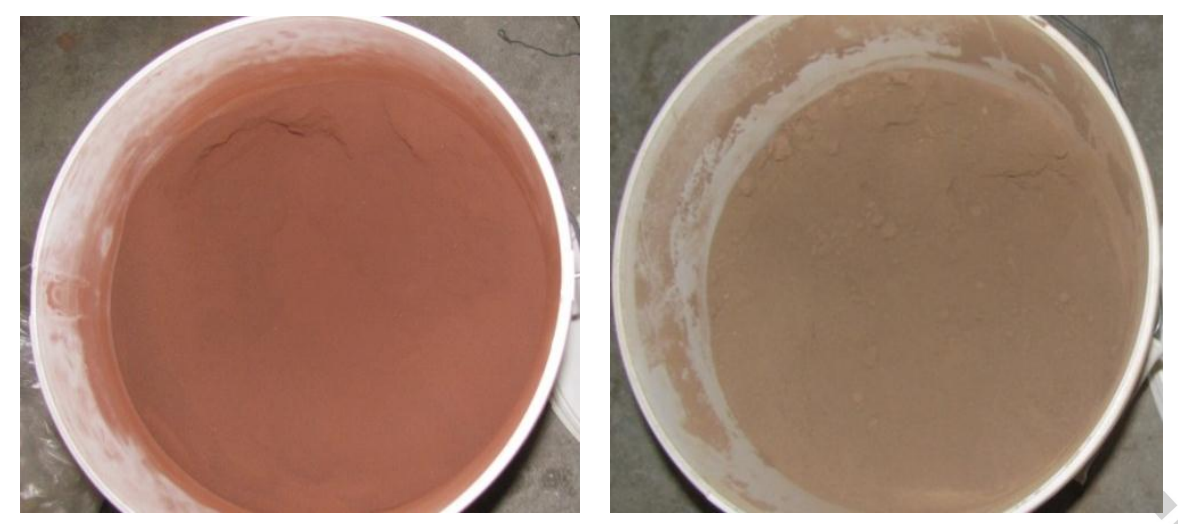

Figure 1

The two investigated SSAs: a) Avedøre ash (AVE) and b) Lynetten ash (LYN)

2.2 Pre-treatment of the ash

Two pre-treatment methods for SSA were used in this study; water washing (W) and grinding $(\mathrm{G})$. Water washing of SSA consisted of 3 washing cycles in distilled water. $100 \mathrm{~g}$ of ash was mixed in a $1 \mathrm{~L}$ plastic bottle with $500 \mathrm{ml}$ of distilled water and agitated for $1 \mathrm{~min}$. The bottle was then placed in a vertical position until the SSA settled. When settled, water was decanted, and the bottle was refilled with a new dose of $500 \mathrm{ml}$ distilled water. This procedure was repeated 3 times. After the last agitation, water and SSA were decanted through a filter paper $(11 \mu \mathrm{m})$ and the wet SSA was dried in an oven at $105{ }^{\circ} \mathrm{C}$. In the alternative pre-treatment method, SSA that had not been washed was ground for $30 \mathrm{sec}$ in a Vibrating Cup Mill Pulverissette 9. The ash was then dried in an oven at $105^{\circ} \mathrm{C}$.

\subsection{Ash characterization}

The characterization and extraction experiments were always performed using ash that had been dried at $105{ }^{\circ} \mathrm{C}$ for 24 hours. An external, commercial laboratory performed $\mathrm{XRF}$ analysis. The morphology was studied by means of a Scanning Electron Microscope (SEM) on either ground or water-washed ash. The accelerating voltage of the SEM was 20-25 kV with a large field detector and X-ray cone. Particle size distributions were measured by laser diffraction using a Malvern Mastersizer 2000. A dry dispersion method for moisture sensitive materials was used. 


\subsection{Preparation of mortar samples}

Reference mortar samples based on cement were prepared according to the standard DS/EN 196-1:2005. For the mortars containing SSA, the same mix design was used, but different proportions of the cement were replaced by SSA. The mortar was cast into prism moulds measuring $4 \times 4 \times 16 \mathrm{~cm}$. The mortar monoliths were cured for 28 days in a water bath (temperature $20.0 \pm 1.0^{\circ} \mathrm{C}$ ). Two ratios of substitution of cement by SSAs were used: $10 \%$ and $30 \%$ by weight (see Table 1). The amounts of added water and sand were the same for all mixtures. A basic Aalborg Portland cement was used (Portland limestone cement, strength class $52.5 \mathrm{~N}$ ) (DS/EN 197-1:2012). Sand from Dansand A/S was used and met the requirements defined by the standard with $\mathrm{D}(0.5)=0.516 \mathrm{~mm}$ (Figure 2).

Table $1 \quad$ Basic mortar recipes used in this work (\% by weight)

\begin{tabular}{lcccc}
\hline Substitution ration [\%] & Cement [g] & SSA [g] & Sand [g] & Water [g] \\
\hline $\mathbf{0}$ (Ref) & 450 & 0 & 1350 & 225 \\
$\mathbf{1 0}$ & 405 & 45 & 1350 & 225 \\
30 & 315 & 135 & 1350 & 225 \\
\hline
\end{tabular}

2.5 Water vapour adsorption test of cement, SSAs and mortar samples

A determination of the hygroscopic sorption properties of cement, ashes and mortar samples was performed in accordance with the standard ISO 12571:2000. Moisture storage in the hygroscopic range was determined as moisture content measured at equilibrium for samples exposed to the various levels of relative humidity (RH).

The standard specifies two alternative methods, using either a desiccator or a climatic chamber. In this study a method using glass desiccators was used for determination of the absorption isotherm. The mortar samples were crushed into grains with a maximum size of $5 \mathrm{~mm}$ and dried at $45^{\circ} \mathrm{C}$. Reference cement-based samples and samples with $30 \%$ cement replacement by SSA were studied. Desiccators, glass weighing cups, a balance and a climatic chamber with constant temperature at $22{ }^{\circ} \mathrm{C}$ were used. The relative 
humidity in each desiccator was maintained with different salt solutions with the following relative humidity: $33 \%, 58 \%, 75 \%, 86 \%$ and $94 \%$. The absorption isotherm was derived for 3 replicates of each sample. The mass of the samples was determined using a Sartorius Research $\mathrm{R} 300 \mathrm{~S}$ balance. The accuracy of these measurements was $\pm 0.2 \mathrm{mg}$.

\subsection{Apparent Density and Open Porosity}

Measurements of apparent volume $\mathrm{V}_{\mathrm{o}}$ and open porosity $\mathrm{P}_{\mathrm{o}}$ followed standard DS/EN 772-4:1998 and was performed on 3 replicates. The mass of each sample was determined using a balance with the accuracy of the measurements $\pm 0.01 \mathrm{~g}$. The apparent density $\rho_{o}$ considers the solid constituents of the material and the pores in combination. It is defined as the ratio of the dry mass $M_{d r y}$ and the volume $V_{o}$ of the dry specimen, see Eq. 1.

$$
\rho_{0}=\frac{M_{d r y}}{V_{0}}
$$

The open porosity or void ratio is the percentage of open pores in the specimen, see Eq. 2 where $V_{\text {pores }}$ is the volume of open pores.

$$
P_{o}=\frac{V_{\text {pores }}}{V_{0}}
$$

2.7 Capillary water absorption

The water absorption test followed standard ISO 15148:2002 and was performed on 3 replicates of the mortar samples. The samples were partially immersed in water so that only the bottom side was in contact with the water. To ensure one-dimensional transport, the samples were sealed with epoxy on the sides. The weight gain of the samples due to water absorption was determined over time at increasing intervals. The water absorption coefficient $A_{w}$ is expressed as a mass of water absorbed by a test specimen per surface area and square root of time. The mass of the samples was determined using a Sartorius Research R 300S balance. The accuracy of the measurements was $\pm 0.2 \mathrm{mg}$.

\subsection{Compressive strength test}


The compressive strength of the mortar samples was assessed after 28 days of curing for six replicates of $4 \times 4 \times 8 \mathrm{~cm}$ monolithic prisms (between the ends of the cast specimen). The compressive strength was measured according to the procedure described in the standard DS/EN 196-1:2005. The work involved nine different mixtures. The substitution ratio of cement varied from $0 \%$ (REF) to $10 \%$ and $30 \%$. Both types of SSAs were used as substitutes with all substitution ratios and with different pre-treatment methods.

3. Results and Discussion

\subsection{Chemical characteristics of the SSAs}

The presence of certain chemical compounds in cement and ash may affect many aspects of mortar casting, such as hydration degree and its rate, workability, or compressive strength. Even when such compounds are only present in little amounts, they may measurably affect the resultant properties of the binder.

The bulk element oxide concentrations are shown in Table 2. Both ashes contained $\mathrm{SiO}_{2}$, $\mathrm{CaO}$ and $\mathrm{Al}_{2} \mathrm{O}_{3}$, which are also major constituents of ordinary cement. It is known that siliceous or siliceous-aluminous materials, if such compounds are present in amorphous state, react chemically with calcium hydroxide at room temperature, forming compounds that possess cementitious properties. Thus pozzolanic activity is directly related to the chemical composition (Malhotra and Mehta, 1996). According to the European standard DS/EN 196-5:2011 "the pozzolanicity is assessed by comparing the concentration of calcium oxide present in the aqueous solution in contact with hydrated cement with the quantity of calcium ion capable of saturating a solution of the same alkalinity. The test provides a positive result if the concentration in the solution is lower than the saturation concentration". Additionally to their pozzolanicity, the physical characteristics of constituent materials also enhance the strength of cementitious systems, including size, shape and texture of the particles (Goldman and Bentur, 1994). It is worth noting that the pozzolanic activity depends on the silica crystallization phase, size and surface area of the ash particles (Zain et al., 2011). The pozzolanic activity of the two ashes was not explicitly studied but it is assumed that the pozzolanicity of SSAs is low compared to that of cement.

In the ashes, the content of $\mathrm{CaO}$ was higher in LYN (36.4\%) than in AVE (23.4\%), but in LYN the content was slightly above half of the content in cement. Cyr et al. (2007) compiled published data on SSA composition and reported that the $\mathrm{CaO}$ content in SSAs 
ranges from $1.1 \%$ to $40.1 \%$, so the two SSAs investigated here were within the normal range of other SSAs. The $\mathrm{SiO}_{2}(15.8 \%)$ and $\mathrm{Al}_{2} \mathrm{O}_{3}(4.4 \%)$ content of AVE was almost that of cement (20.1\% and $4.9 \%$, respectively), while $\mathrm{LYN}$ contained less $\mathrm{SiO}_{2}(14.3 \%)$ and $\mathrm{Al}_{2} \mathrm{O}_{3}(2.7 \%)$. The $\mathrm{SiO}_{2}$ and $\mathrm{Al}_{2} \mathrm{O}_{3}$ contents of the $\mathrm{AVE}$ were within the ranges reported by Cyr et al. (2007): $14.4-65 \% \mathrm{SiO}_{2}$ and $4.4-34.2 \% \mathrm{Al}_{2} \mathrm{O}_{3}$.

It is worth noting that the content of phosphorus pentoxide $\left(\mathrm{P}_{2} \mathrm{O}_{5}\right)$ was much higher in the SSAs compared to the cement. A similar range of $\mathrm{P}_{2} \mathrm{O}_{5}$ concentration in SSA was observed by $\mathrm{Cyr}$ et al. (2007): $0.3-26.7 \%$. A high content of $\mathrm{P}_{2} \mathrm{O}_{5}$ results in longer setting times and slow development of strength (Lin et al., 2009; Naamane et al., 2016; Nurse, 1952). Regarding the concentration in cement, Hewlett (2004) stated that $\mathrm{P}_{2} \mathrm{O}_{5}$ is occasionally present in small amounts in the raw materials of cement manufacture and in such cases it passes into the clinker. If present in quantities of $1-2 \%$ in Portland cement clinker it slows the rate of hardening of the cement (Hewlett, 2004). As reported in Table 2, adding SSA to the mortar mixture increased the total content of $\mathrm{P}_{2} \mathrm{O}_{5}$. This may adversely affect the setting and hardening of the mortar and so may reduce the compressive strength of the material. When $10 \%$ of the cement was replaced by AVE ash, the content of $\mathrm{P}_{2} \mathrm{O}_{5}$ increased by approximately $1.8 \%$ compared to cement-based mortar, and with a replacement ratio of $30 \%$ the $\mathrm{P}_{2} \mathrm{O}_{5}$ content increased by $5.2 \%$. In the case of cement replaced by LYN ash with replacement ratios of $10 \%$ and $30 \%$, the $\mathrm{P}_{2} \mathrm{O}_{5}$ content increased by approximately 1\%, and 3\%, respectively. Such elevated concentrations of $\mathrm{P}_{2} \mathrm{O}_{5}$ may adversely affect the rate of strength development. However, recent strategies focus on phosphorus removal from SSAs before its use as an SCM.

The content of the 5 oxides with the highest concentrations (Table 2) in the two SSAs were for AVE: $\mathrm{CaO}>\mathrm{P}_{2} \mathrm{O}_{5}>\mathrm{Fe}_{2} \mathrm{O}_{3}>\mathrm{SiO}_{2}>\mathrm{Al}_{2} \mathrm{O}_{3}$ and for $\mathrm{LYN}: \mathrm{CaO}>\mathrm{SiO}_{2}>\mathrm{P}_{2} \mathrm{O}_{5}>$ $\mathrm{Fe}_{2} \mathrm{O}_{3}>\mathrm{SO}_{3}$, which reveals, that the two SSAs are of significantly different composition. The higher content of $\mathrm{Fe}_{2} \mathrm{O}_{3}$ in AVE than LYN corresponds well with the stronger red colour of AVE (Figure 1), which is due to the presence of iron oxides added during incineration process. In general, the oxide contents of the two studied ashes varied within a typical range of concentration values, or were just in the low end of the range.

Table 2 Major oxide content and chloride content present in the cement, coal fly ash and SSAs

\begin{tabular}{llllll}
\hline $\begin{array}{l}\text { Major oxide } \\
\text { content [\%] }\end{array}$ & Cement & $\begin{array}{l}\text { Coal } \\
\text { fly ash* }\end{array}$ & $\begin{array}{l}\text { Avedøre } \\
\text { not treated }\end{array}$ & $\begin{array}{l}\text { Lynetten } \\
\text { not treated }\end{array}$ & SSA** \\
\hline $\mathrm{MgO}$ & 0.53 & $0.1-6.7$ & 1.82 & 1.99 & $0.02-23.4$ \\
$\mathrm{Al}_{2} \mathrm{O}_{3}$ & 4.91 & $2.6-20.5$ & 4.4 & 2.65 & $4.4-34.2$ \\
\hline
\end{tabular}




\begin{tabular}{cccccc}
\hline $\mathrm{SiO}_{2}$ & 20.1 & $11.8-46.4$ & 15.83 & 14.33 & $14.4-65.0$ \\
$\mathrm{CaO}$ & 65.8 & $15.1-54.8$ & 23.37 & 36.38 & $1.1-40.1$ \\
$\mathrm{TiO}_{2}$ & 0.35 & $0.6-1.0$ & 0.83 & 0.67 & $0.3-1.9$ \\
$\mathrm{Fe}_{2} \mathrm{O}_{3}$ & 5.43 & $1.4-15.6$ & 16.30 & 7.15 & $2.1-30.0$ \\
$\mathrm{MnO}$ & 0.04 & $0.1-6.7$ & 0.09 & 0.05 & $0.03-0.9$ \\
$\mathrm{~K}_{2} \mathrm{O}$ & 0.81 & $0.3-9.3$ & 1.45 & 1.81 & $0.1-3.1$ \\
$\mathrm{Na}_{2} \mathrm{O}$ & $<0.67$ & $0.2-2.8$ & 0.67 & 0.81 & $0.01-6.8$ \\
$\mathrm{P}_{2} \mathrm{O}_{5}$ & 0.23 & $0.2-0.4$ & 18.33 & 10.31 & $0.3-26.7$ \\
$\mathrm{SO}_{3}^{-}$ & 4.74 & $1.4-12.9$ & 2.00 & 4.74 & $0.01-12.4$ \\
$\mathrm{Cl}^{-}$ & 0.1 & -- & $<0.01$ & 0.2 & -- \\
\hline
\end{tabular}

*Source: Hemalatha and Ramaswamy (2017) (coal fly ash Class C)

** Source: Cyr et al. (2007) (range of typical min and max values based on literature review)

The oxide content of SSAs was compared to the coal fly ash described in the study by Hemalatha and Ramaswamy (2017) as coal fly ash was used for decades as SCM (Chandra, 1997). The coal fly ash is defined in standard as a fine powder consisting mainly of spherical glassy particles formed during the combustion of pulverized coal. Coal fly ash is obtained by electrostatic or mechanical precipitation of ash particles in the exhaust gases of power plants that combust coal. Similar to cement, coal fly ash contains the reactive oxides $\mathrm{SiO}_{2}$ and $\mathrm{Al}_{2} \mathrm{O}_{3}$. The reactive content of $\mathrm{SiO}_{2}$ according to standard DS/EN 197-1:2012 must be at least 25\% of the ash to be classified as siliceous. However, it is important to note that cement and ash origin are different and this will affect the way the compounds react. Danish coal fly ash, due to its chemical composition and type of combustion, meets the requirements to be classified as siliceous (Nielsen, 1985). Nevertheless, there are no corresponding requirements for SSA as an SCM in concrete.

\subsection{Particle size distribution of cement and SSA and grain morphology}

The particle size distribution and morphology of cement and ash grains have a significant effect on the heat of hydration, the progress of hydration and consequently on mortar 
porosity and its compressive strength (Frigione and Marra, 1976; Monzó et al., 1996). The compressive strength increases with an increasingly narrow particle size distribution (at constant specific surface area), i.e. for equal specific surface areas the strength increases as the grain size distribution becomes narrower. This implies that the heat of hydration and the amount of hydration product both increase when the particle size distribution becomes narrower (Lawrence, 1998). The fineness of a particle and the related specific surface area both have a strong effect on the rate at which the cement hydrates when exposed to water (Chen and Poon, 2017; Lin et al., 2005). If an ash is used as a substitute for cement in mortar production, the smallest particles, with the largest relative surface area, being the most reactive, would act as a binder whereas the biggest particles, being much less reactive, would mainly act as a filler (Chen et al., 2013).

The grain size distribution for cement, SSAs and sand are seen in Figure 2. LYN is clearly characterized by finer particles compared to AVE, both in the as-received form $(\mathrm{R})$ and when it had been ground (G). Figure 2 a) shows that after $30 \mathrm{sec}$ of grinding, the particle size distribution was shifted and had become closer to that of cement, compared to non-ground samples, as expected. In Figure 2 b), the water-washed (W) ashes follow the curve of untreated ash.

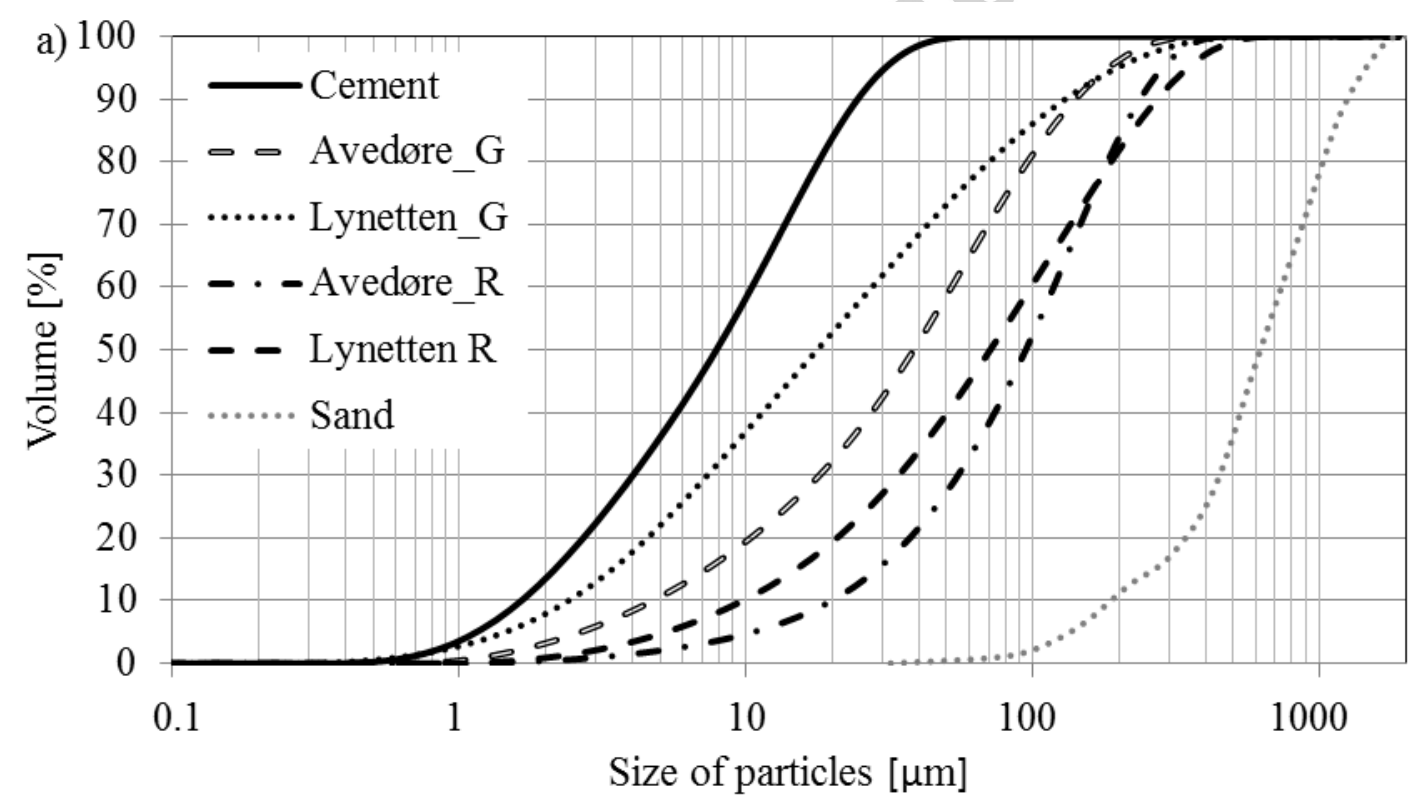




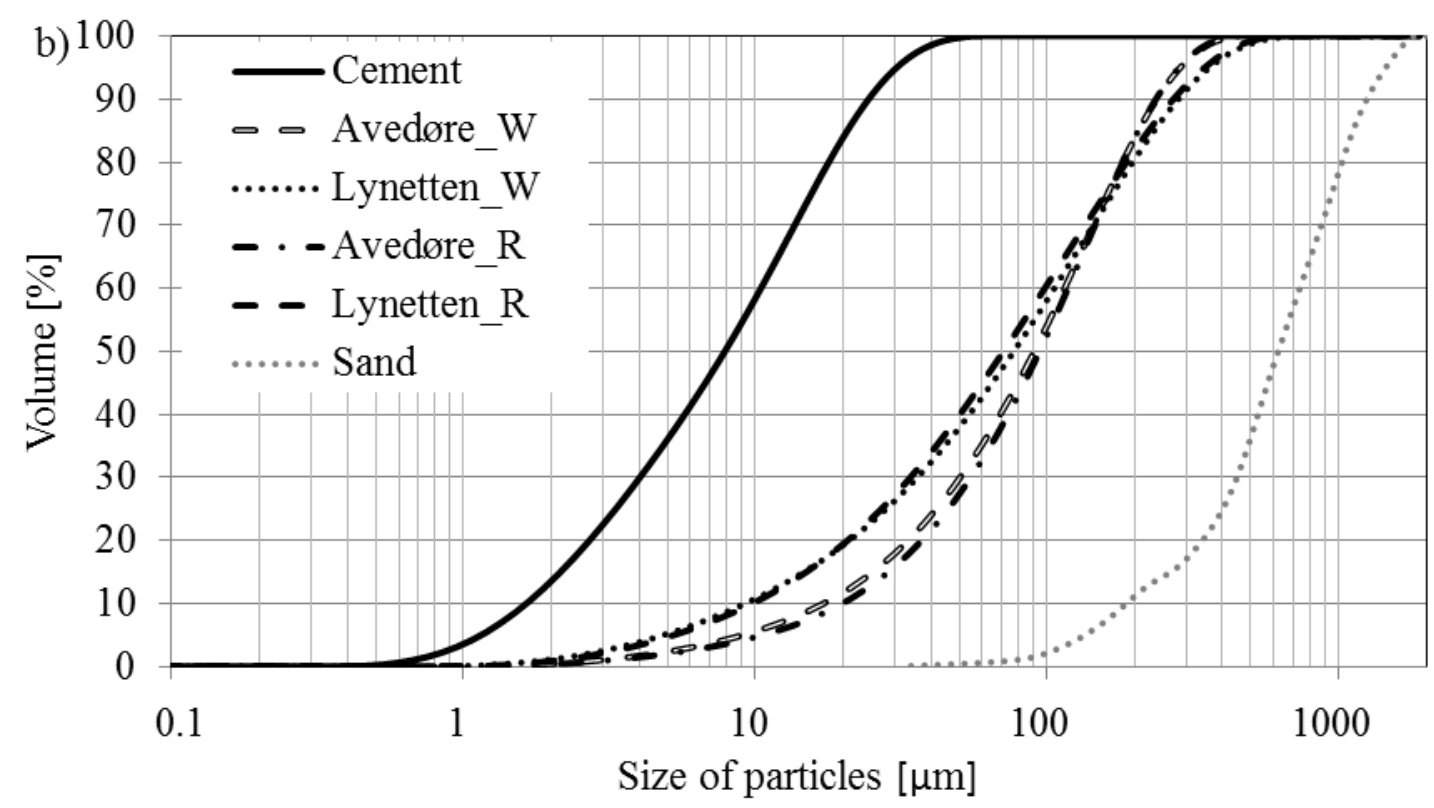

Figure 2 Particle size distribution - undersize curves; comparisons of Basis cement and SSAs. a) Cement, untreated (R) ash, ash ground (G) for $30 \mathrm{sec}$ and sand b) Cement, untreated (R) ash, water-washed (W) ash and sand

Figure 3 shows SEM images of the SSAs in both raw and treated forms. The SSA particles were irregular and porous, confirming the previous report by Donatello and Cheeseman (2013). Observations based on SEM images supported with the observed results from the particle size distributions shown above. Grinding, even only for $30 \mathrm{sec}$, improved the fineness of the grains (also reported by Kappel et al. (2018)), while the water-washing pre-treatment did not change the morphology.
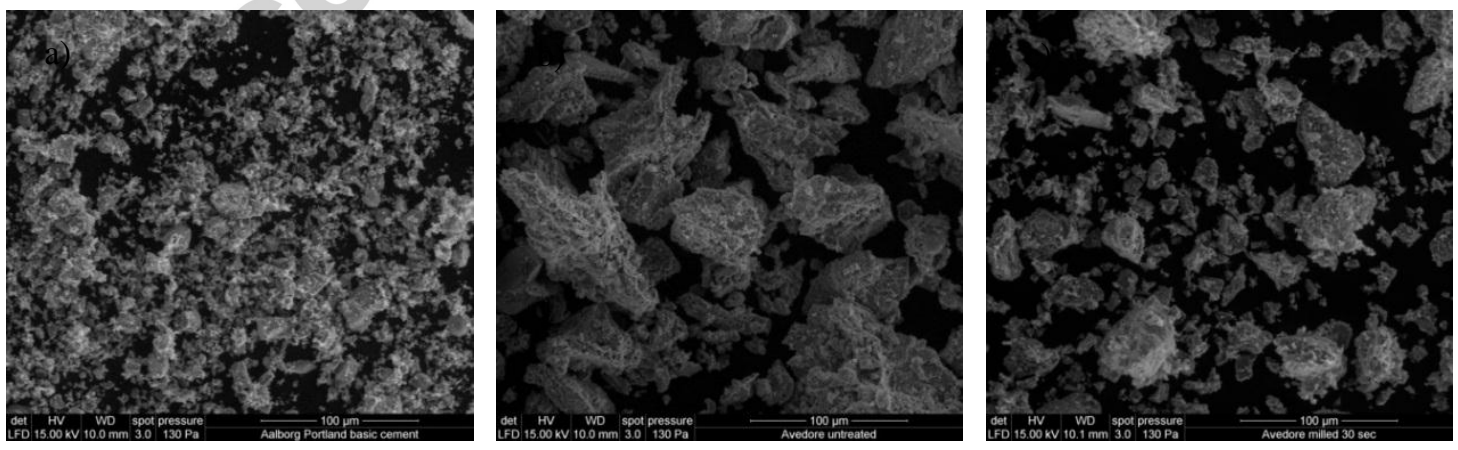

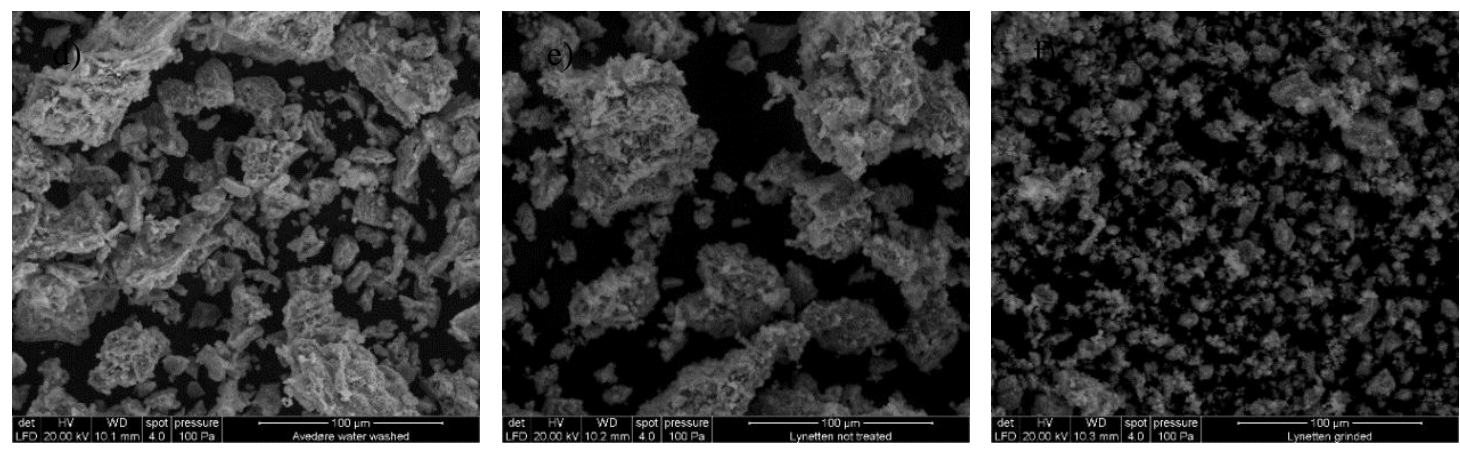

Figure 3 Scanning electron microscope images a) cement, b) AVE not treated, c) AVE grinded for $30 \mathrm{sec}$, d) AVE water washed, and e) LYN not treated, f) LYN grinded for $30 \mathrm{sec}$

Sewage sludge ash characteristics obtained by Lynn et al. (2015) show that the above grain size distributions correspond to the range of particle size that characterizes silt $(2.5-62.5) \mu \mathrm{m}$ and fine sand $(62.5-250) \mu \mathrm{m}$. In the present study of the ashes from Lynetten and Avedøre, particle size varied approximately from 1 to $400 \mu \mathrm{m}$ for untreated ash, while cement particles were in the range $(0.4-50) \mu \mathrm{m}$. The median particle size of Portland cement was $\mathrm{D}(0.5)=8.3 \mu \mathrm{m}$, while for the SSAs, $\mathrm{D}(0.5)=100 \mu \mathrm{m}$ was the median particle size for AVE and $\mathrm{D}(0.5)=75 \mu \mathrm{m}$ for LYN. For comparison, sand has a particle size range that extends up to $2000 \mu \mathrm{m}$ with a median particle size $\mathrm{D}(0.5)=$ $520 \mu \mathrm{m}$ (Figure 2)).

The particle size range of the ashes was evidently larger than that of Basis Aalborg Portland cement. Additionally, cement had a narrower particle size distribution curve than the SSAs. This may adversely affect the rate of hydration of the mortar mixture. Several studies tested the hydration of cement-based and cement-ash-based pastes (Chen and Poon, 2017; Dyer et al., 2001; Hu et al., 2014; Lin et al., 2005). Chen and Poon (2017) reported that no heat release was measured when a paste contained only SSA and no cement, indicating that SSA does not possess any hydration activity in itself, and this was confirmed by Cyr et al. (2007). On the other hand, the peak hydration rates of a paste containing both cement and SSA were reported to be higher than those of cement paste (Chen and Poon, 2017). This is probably due to the porous structure of SSA that entraps water in its pores, leading to a higher concentration of cement particles in water, i.e. a lower effective water to cement ratio ( $\mathrm{Hu}$ et al., 2014) that exceeds the dilution effect of the cement (Lawrence et al., 2003) that was replaced by SSA. The effect of the grain size distribution and morphology of the two specific SSAs after different pre-treatments on the hydration progress of mortar was not part of the study but would be a suitable subject for further investigations. 
The water vapour adsorption capability of cement and of ground and water-washed SSAs are shown in Figure 4. Adsorption data for mortar samples are presented for comparison in Figure 4, and these results will be further discussed in a later report of the study. The graph clearly reveals that the moisture adsorption of cement is higher than that of the SSAs when exposed to identical conditions. The effect of relative humidity on cement hydration has been studied by some authors, although most of them studied cement pastes, e.g. (Patel et al., 1988; Powers, 1948; Wyrzykowski and Lura, 2016). They reported that hydration virtually ceased below about $80 \% \mathrm{RH}$. These results indicate that the amount of water in the capillary structure of the paste is important for hydration to proceed (Patel et al., 1988). The cement data in Figure 4 show that the steepest increase of the adsorption curve was observed above $70 \% \mathrm{RH}$, which lends support to the previous experimental observations. The last step in the sorption curve of cement (dashed line from $86 \%$ to $94 \%$ ) demonstrates a step that did not reach equilibrium for the conditions at $94 \% \mathrm{RH}$, while the ashes did so. This may be due to the reactions of the cement clinker components with water as cement requires a long period of time to become fully hydrated (Nilsson, 1980). When water is present as vapour, the cement reactions are slower than when water is present in the liquid phase, so cement continued to react with water vapour, while the SSAs had already reached equilibrium. These observations are in agreement with the statement by Chen and Poon (2017) that SSA does not hydrate itself, it just entraps water in its pores.

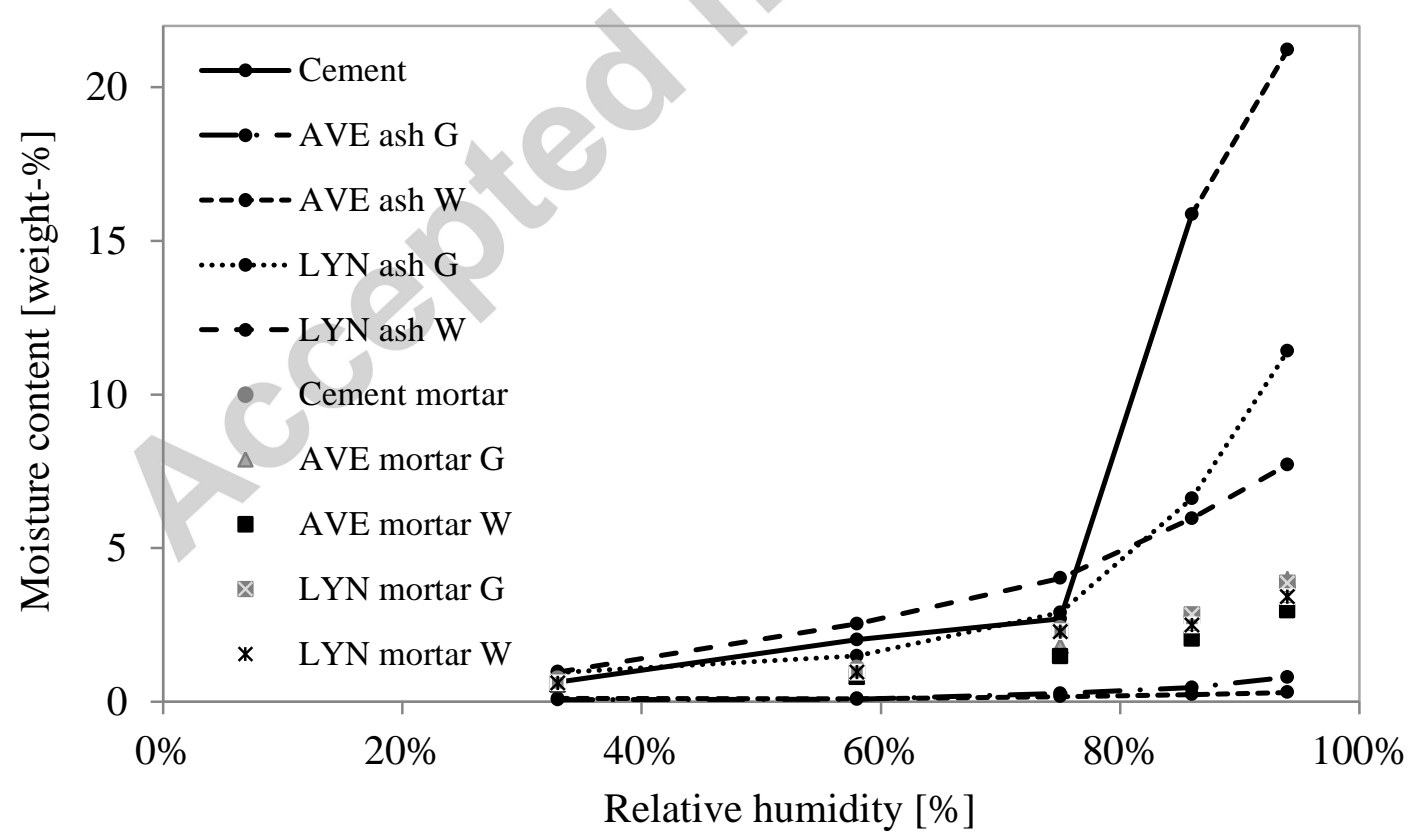

Figure $4 \quad$ Sorption isotherms of the cement, treated SSAs, cement mortar and mortar with $30 \%$ treated SSA as SCM. (AVE - Avedøre ash, LYN - Lynetten ash, G - ground, $\mathrm{W}$ - water-washed). The sorption curve of cement did not reach equilibrium above $86 \%$ $\mathrm{RH}$ and the line is thus dashed 
By comparing the adsorption curves of the SSAs it can be seen that each SSA has a different sorption capacity. It is evident that LYN ash adsorbed more moisture at all values of $\mathrm{RH}$, both in the ground and water-washed form, compared to AVE. For example, AVE adsorbed less than 1 weight-\% at $94 \% \mathrm{RH}$, whereas at the same $\mathrm{RH}$, water-washed LYN adsorbed more than $7 \%$ water by weight, and ground LYN ash adsorbed even more water vapour. This is linked to the finer particle sizes of LYN ash (Figure 2), which gives it a larger relative surface area. Comparing the different pretreatment methods, the ground SSAs had higher water vapour sorption capacity at the highest RH than the water-washed samples. Although grinding increased the relative surface area of grains (Chen and Poon, 2017; Pan et al., 2003a), this might also be due to the presence of water-soluble hygroscopic salts in ground ash, while these were washed out or were incorporated into new particles in the water-washed SSAs.

In addition to the adsorption isotherms for the treated SSAs, Figure 4 also shows the sorption values of hardened mortars: cement mortar and mortars containing the SSAs (30\% as an SCM). The sorption results of different mortar compositions almost overlap each other over the major part of the relative humidity range in the common scale perspective for ashes and mortar. Minimal or no differences in mortar adsorption were found between the different ash pre-treatments. Based on a comparison of sorption curves for cement and SSA particles, where differences between the individual components are clearly visible, the measurements of the mortars were not, or only to a minimal extent affected by replacement of up to $30 \%$ of the cement content. However, there was a tendency for the mortar with washed SSA to be slightly lower in water vapour sorption than mortar containing ground ash.

\subsection{Open porosity and apparent density of mortar}

The porosity of a material normally has a considerable influence on its physical properties. Mortar is a porous solid, which by its nature has properties based on its constituents and their chemical reactivity. When a concentrated suspension of cement and ash in water is allowed to hydrate, the reaction products are formed as a coherent matrix that encloses the residues of non-hydrated grains. The hydration process may take place over a long period, even after the set hardening period, and the matrix retains some of its porosity while hydration continues (Lawrence, 1998). This implies that the density and porosity of the material reflects the hydration state of the mortar. A simple empirical relationship between strength and porosity has been found in data for hardened cement pastes (Rößler and Odler, 1985). A reduction of porosity in a solid material increases its strength in general, and the strength of cement-based materials in particular (Etris et al., 1973; Yudenfreund et al., 1972). The compressive strength and its relation to porosity will be discussed further in the following section. It is to be expected that SSA would have a considerable effect on mortar porosity, as SSA itself is a porous material. 
However, for the benefit of mortar compactness, the pores in an SSA might serve as a place to accommodate hydration products (Zhou et al., 2010).

The apparent density and open porosity of the different mortars (Figure 5) indicate a minor influence of ash content on apparent density, while its influence on porosity was more obvious. The density slightly decreased (and the porosity increased) as the content of SSA increased, which may be because the SSA had a lower density than the cement or because of the irregular morphology of ash grains (Baeza-Brotons et al., 2014). It is clear that the increase of porosity was linked to the decrease of density, as these two parameters are directly related. The lowest porosity was observed for the REF mortar where only cement was present. Such a phenomenon is based on the fact that cement is reactive with water and thus has lower porosity at equal density. In general, a small effect of ash content on porosity was observed with $10 \%$ cement replacement by SSA (AVE10G, LYN10G) compared to REF. As Chen and Poon (2017) reported, substitution of up to $10 \%$ of cement by SSA balances the effect of higher porosity with improved hydration of cement, using the water absorbed in the ash pores. An increase in porosity by more than $20 \%$ was found for AVE30W compared to REF. It has been shown in the previous section that simple grinding for $30 \mathrm{sec}$ provided finer ash grains. This resulted in no significant changes in the porous structure of the material when only $10 \%$ of the cement was replaced, for example for AVE10G vs. AVE10W, and LYN10G vs. LYN10W. The effect of ash grinding was slightly visible at a replacement ratio of $30 \%$, i.e. when comparing AVE30G with AVE30W. These observations imply that mortar porosity increased with increased ash to cement ratio. Additionally, the porosity of the mortar with ground SSAs slightly decreased as the fineness of the SSA increased.

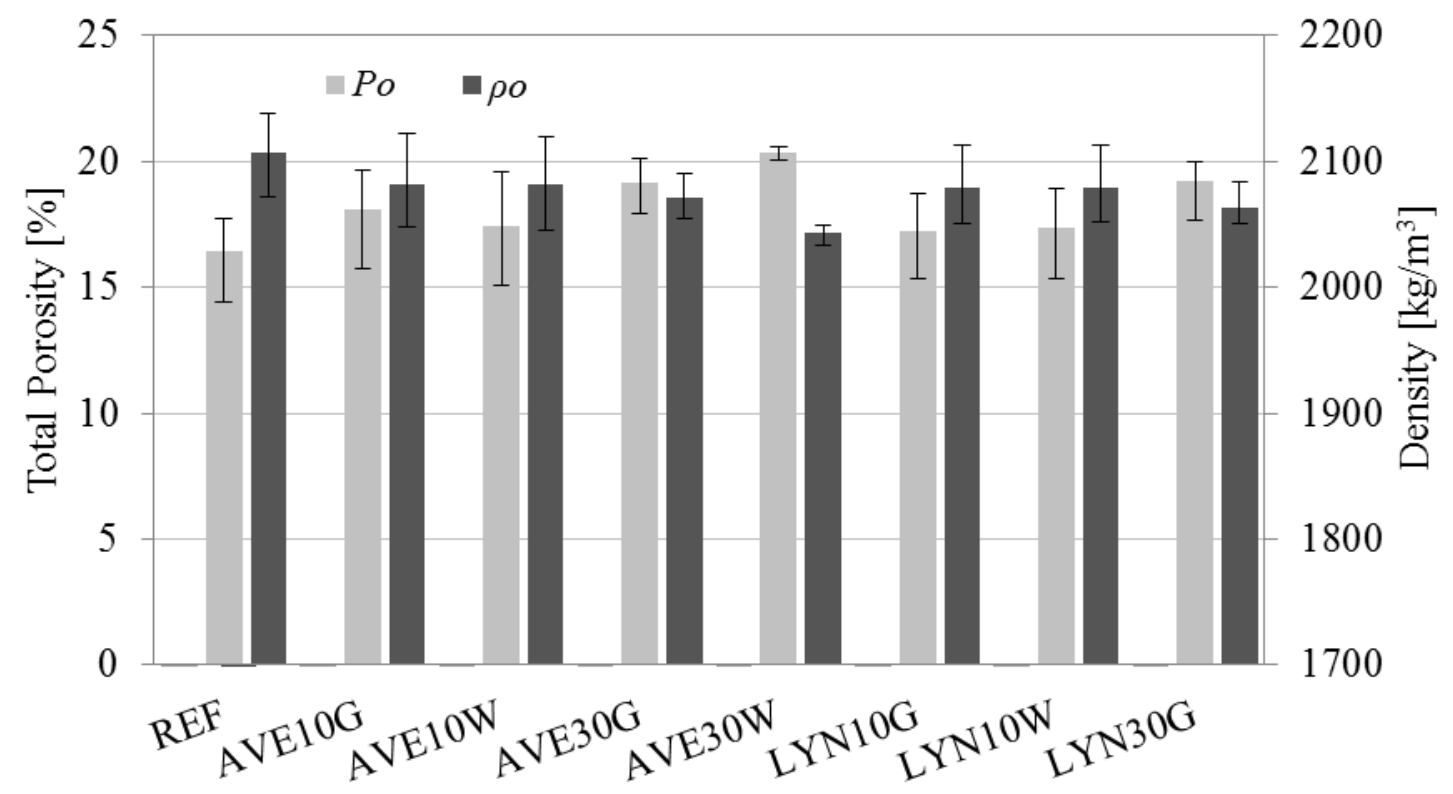

Figure 5 Apparent density $\rho_{0}$ and open porosity $P_{o}$ including standard deviation 


\subsection{Capillary absorption (Water uptake)}

The results of the capillary water absorption tests are shown in Figure 6 as water absorption coefficients. Only the linear transient part of the measured curve was considered. As proof of the accuracy of the measured data, results from two time-periods are presented: one period considered immersion time intervals between 5 minutes and 2 hours, while the second considered intervals between 5 minutes and 4 hours. As may be seen, the water absorption coefficient increased significantly with the ash to cement ratio, but it was not affected either by ash type or ash pre-treatment method. Mortars containing $30 \%$ SSA had water-absorption coefficients of about 2.5 times the value for REF cement mortar. This indicates that the higher porosity of the mortars that contain SSA have more pores in the capillary range than the purely cement-based mortar. The fineness of the SSA has no significant influence on the capillary water absorption of the cast mortar. However, the water absorption coefficient is slightly higher for AVE30G compared to AVE30W. This slight difference may be due to an increased number of capillary pores in AVE30G, as the grinding pre-treatment leads to a finer particle size and higher surface area (Hu et al., 2014; Pan et al., 2003a).

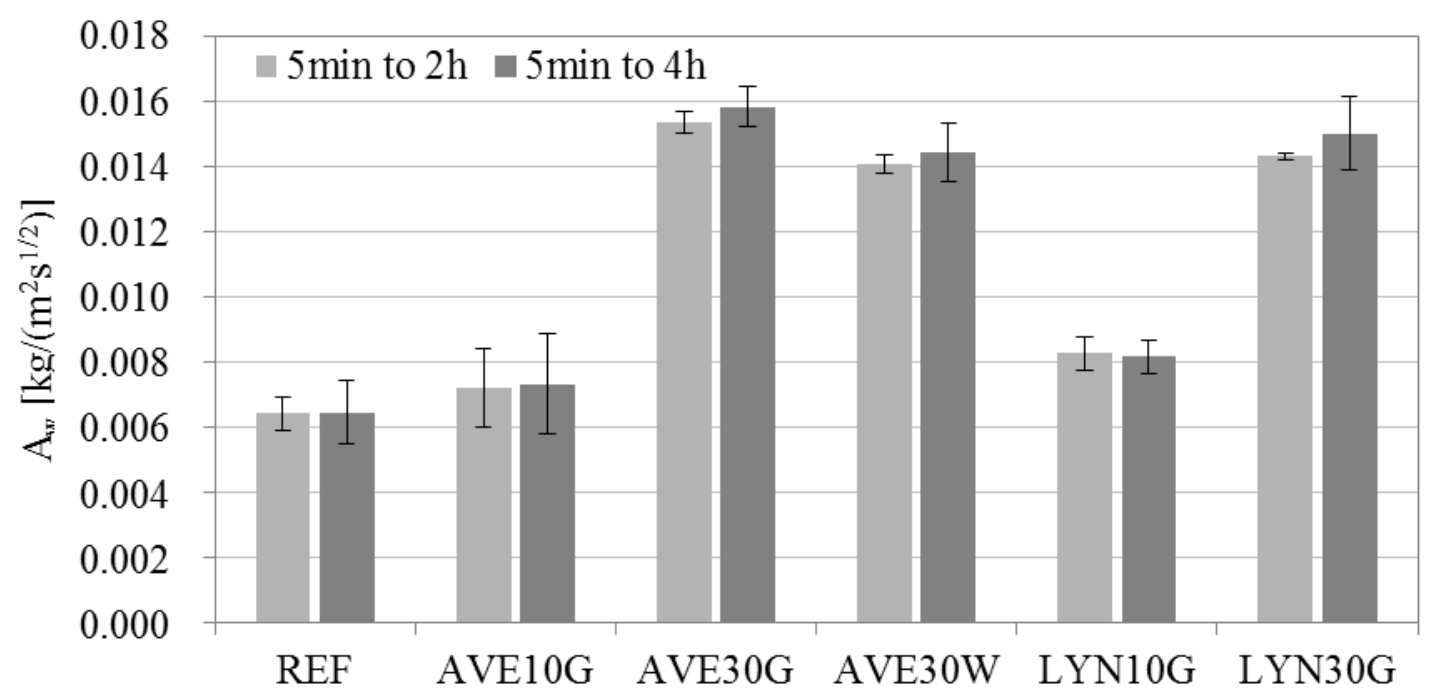

Figure 6 Water absorption coefficients for mortars with different grades of SCM and their standard deviations. $A_{w}$ was determined for two different time intervals 
Compressive strength is one of the most important characteristics of a structural building material. This parameter was therefore included in the test schedule despite the large amount of published data on the subject. A test of compressive strength was performed in order to investigate the practical applicability of mortar with a high cement replacement ratio by SSA. It is well known that compressive strength may be affected by the presence of both major and minor components in clinker and ash, the specific surface area of grains, the particle size distribution and the microstructure of grains (Lawrence, 1998). Some of these aspects were already discussed above.

It was observed that the mixtures in the fresh state containing ash had less workability when compared to the mixture with no ash, although the consistency was still sufficiently liquid for casting to be possible without adding extra water. This may be caused by the irregular shape (unlike coal fly ash with its spherical grain shape) of the ash particles, by the porous structure of the SSAs' particles (Donatello, 2009) and high content of $\mathrm{P}_{2} \mathrm{O}_{5}$ (Lawrence, 1998; Nurse, 1952) adversely affecting workability, setting time and strength development. This implies that either some of the water added during casting may be absorbed by the irregular particles of ash, or that $\mathrm{P}_{2} \mathrm{O}_{5}$ forms a matrix, while consuming the water, with the reactive $\mathrm{CaO}$ and $\mathrm{SiO}_{2}$ reducing their availability for pozzolanic reactions and resulting in longer setting time and delays of hydration (Piasta and Lukawska, 2016) and subsequently in strength drop (Nurse, 1952). As a consequence of irregular shape of particles, less water is available to provide proper workability than for the reference cement-based mortar. Whether this water is still available for the hydration process or is permanently captured by the particles has not been investigated.

Figure 7 shows the compressive strength of the mortar samples of this investigation after 28 days of curing. The compressive strength, in general, decreased with increasing ash content compared to the reference mortar. It has previously been studied that grinding of SSA may improve the ash quality with respect to its use as an SCM (Donatello et al., 2010; Kappel et al., 2017; Ottosen et al., 2013; Pan et al., 2003b). The results obtained in this study support the previous findings (Ottosen et al., 2013), in which increased compressive strength was reported for samples containing SSA that had been ground for $30 \mathrm{sec}$ compared to SSA treated by water washing. A more evident effect was observed for $30 \%$ cement replacement by SSA, in terms of compressive strength loss. 


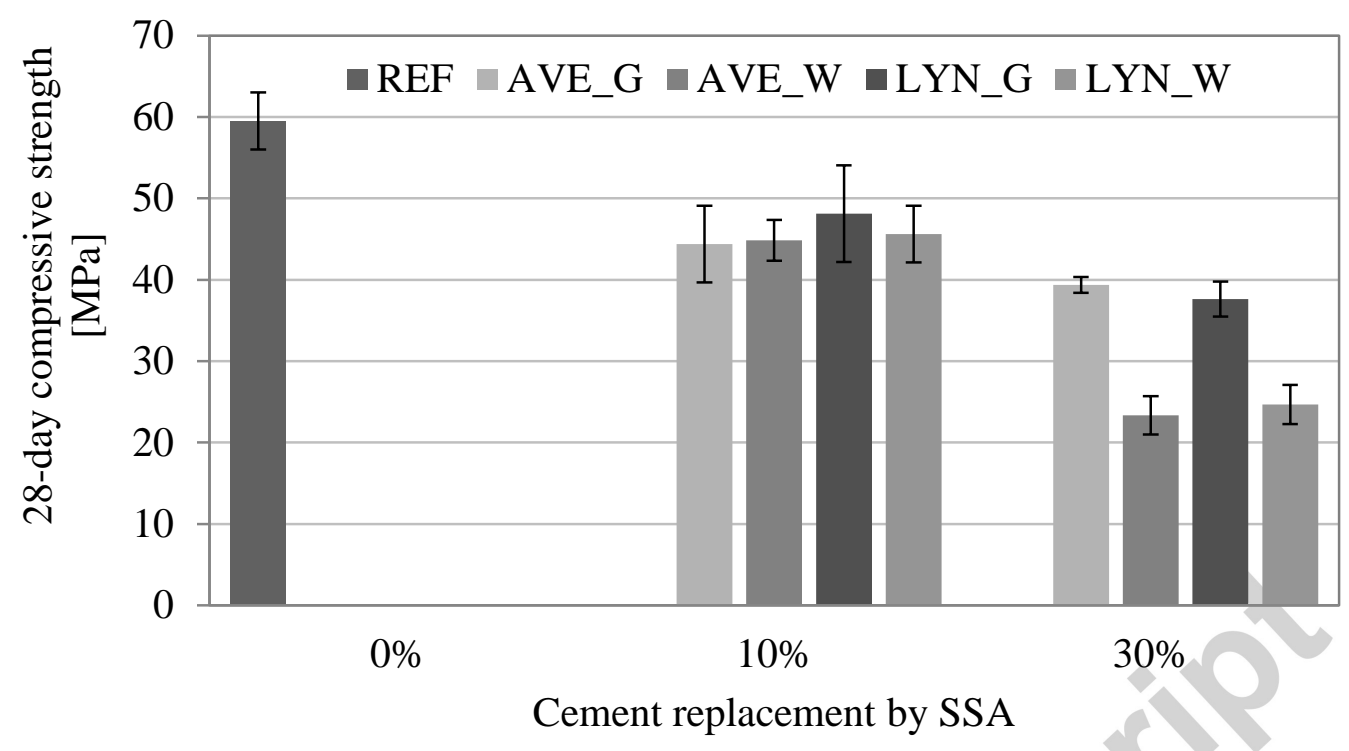

Figure 7 28-day compressive strengths of mortar test specimens

The mortar strength is primarily dependent on the binder, the water to cement ratio, its porosity and its density. Higher material porosity would result in a lower final strength of the material. In the present study, replacement of $30 \%$ cement content by the pre-treated SSA resulted in an increase in porosity of more than $20 \%$ and a decrease in compressive strength of more than $50 \%$ at 28 days (AVE30W). The mortar with the lowest cement to ash ratio possessed the highest porosity and thus the lowest compressive strength, as expected. The water to binder ratio was kept constant, but the water to cement ratio increased from 0.5 to 0.7 , which must also be expected to influence the compressive strength (as well as the porosity), as the SSA does not directly substitute for the hydration reactions of the cement. Several studies tested the compressive strength of mortar with various cement substitution ratios (up to 20\%) at different ages, i.e. 7-day, 28-day and 90day (Chen and Poon, 2017; Cyr et al., 2007; Jamshidi et al., 2012; Naamane et al., 2016). As in the observations described above, it was unanimously reported that, with increased substitution ratio of cement by SSA, compressive strength decreased. However, it was also reported in the foregoing publications that the compressive strength continuously developed over time for all the samples (both cement-based and cement-ash-based) at all time periods. There are some possible explanations of strength development of cementash-based mortar over time: firstly the water absorbed by the ash pores reduces the water to binder ratio, which counterbalances the dilution effect (i.e. higher water to cement ratio), secondly the water absorbed by the ash pores may be released back to the matrix allowing additional hydration of cement. Additionally, the irregular shape of ash particles enhances the interlocking among grains of ash and cement and supporting overall strength.

\section{Conclusions}


Two sewage sludge ashes (SSA) with two different pre-treatments, namely water washing and grinding, were studied in this investigation to ascertain the consequences of using them as supplementary cementitious material (SCM) with replacement levels of $10 \%$ and $30 \%$ of the cement in mortar. Both ashes contained silicon dioxide $\left(\mathrm{SiO}_{2}\right)$, aluminium oxide $\left(\mathrm{Al}_{2} \mathrm{O}_{3}\right)$ and iron oxide $\left(\mathrm{Fe}_{2} \mathrm{O}_{3}\right)$ similarly to cement, so some cementitious properties may be anticipated. However, no XRD analysis was carried out to ascertain degree of crystallinity and to establish pozzolanicity. In addition, a high content of phosphorus pentoxide $\left(\mathrm{P}_{2} \mathrm{O}_{5}\right)$ was detected, which may adversely affect the mortar setting and hardening process.

Sorption isotherms showed that the hygroscopic water vapour absorption of the two types of SSA was different. For one of the ashes, the adsorption was less than $1 \%$ by mass at 94\% RH, regardless of the pre-treatment method, while the other absorbed more than $7 \%$ at the same RH (the ground ash more than the water washed ash). The difference is believed to be due to differences in the fineness of the particles and in the content of hygroscopic salts. However, the effect of the SCMs on the water vapour sorption of the cast mortars was minor, even with $30 \%$ cement substitution. It was concluded that the final mortars are not significantly affected by the sorption properties of cement and SSAs.

Particle size distributions indicated larger grain sizes of SSA compared to cement. Finer particle sizes were achieved by grinding the ash as a pre-treatment. Pre-treatment by water washing did not influence the particle size distribution. The porosity of mortar was clearly affected by the particle size of each constituent. The mortars with the highest ratio of SSA were the most porous. Generally, the porosity was slightly influenced by the pretreatment method at the highest ratio of cement substitution. Similarly, the capillary water absorption coefficient increased in mortars with SSA compared to the reference cementbased mortar and with increasing SSA content. The particle size distribution clearly affected the compressive strength, and even $10 \%$ cement substitution by SSA caused a significant decrease in the 28-day compressive strength of mortar. At cement to ash ratio of (7:3), clear differences between ash pre-treatment methods were observed: grinding the ash resulted in improved compressive strength compared to the water-washing pretreatment.

Declaration of conflicting interests

The author(s) declared no potential conflicts of interest with respect to the research, authorship, and/or publication of this article.

Acknowledgements

The present research project formed part of the ZeroWaste development area established at the Department of Civil Engineering, Technical University of Denmark. 
Funding statement

This work has been funded by the Technical University of Denmark, Department of Civil Engineering, as an activity under the strategic innovation initiative "ZeroWaste Byg".

The reference: http://www.byg.dtu.dk/english/innovation-and-public-sector-consultancy.

\section{References}

Ahmaruzzaman, M., 2010. A review on the utilization of fly ash. Prog. Energy Combust. Sci. 36, 327-363. https://doi.org/10.1016/j.pecs.2009.11.003

Baeza-Brotons, F., Garcés, P., Payá, J., Saval, J.M., 2014. Portland cement systems with addition of sewage sludge ash. Application in concretes for the manufacture of blocks. J. Clean. Prod. 82, 112-124. https://doi.org/10.1016/j.jclepro.2014.06.072

Benhelal, E., Zahedi, G., Shamsaei, E., Bahadori, A., 2013. Global strategies and potentials to curb $\mathrm{CO} 2$ emissions in cement industry. J. Clean. Prod. https://doi.org/10.1016/j.jclepro.2012.10.049

Chandra, S., 1997. Waste materials used in concrete manufacturing. Noyes Publications, Westwood, N.J., U.S.A.

Chen, C.-H., Chiou, I.-J., Wang, K.-S., 2006. Sintering effect on cement bonded sewage sludge ash. Cem. Concr. Compos. 28, 26-32. https://doi.org/10.1016/j.cemconcomp.2005.09.003

Chen, M., Blanc, D., Gautier, M., Mehu, J., Gourdon, R., 2013. Environmental and technical assessments of the potential utilization of sewage sludge ashes (SSAs) as secondary raw materials in construction. Waste Manag. 33, 1268-1275. https://doi.org/10.1016/j.wasman.2013.01.004

Chen, Z., Poon, C.S., 2017. Comparative studies on the effects of sewage sludge ash and fly ash on cement hydration and properties of cement mortars. Constr. Build. Mater. 154, 791-803. https://doi.org/10.1016/j.conbuildmat.2017.08.003

Connolly, K., 2015. G7 leaders agree to phase out fossil fuel use by end of century. The Guardian.

Cyr, M., Coutand, M., Clastres, P., 2007. Technological and environmental behavior of sewage sludge ash (SSA) in cement-based materials. Cem. Concr. Res. 37, 12781289. https://doi.org/10.1016/j.cemconres.2007.04.003

Donatello, S., 2009. Characteristics of incinerated sewage sludge ashes: potential for phosphate extraction and re-use as a pozzolanic material in construction products (PhD Thesis). Imperial College, Department of Civil and Environmental Engineering, London.

Donatello, S., Cheeseman, C.R., 2013. Recycling and recovery routes for incinerated sewage sludge ash (ISSA): A review. Waste Manag. https://doi.org/10.1016/j.wasman.2013.05.024

Donatello, S., Tyrer, M., Cheeseman, C.R., 2010. Comparison of test methods to assess pozzolanic activity. Cem. Concr. Compos. 32, 121-127. https://doi.org/10.1016/j.cemconcomp.2009.10.008

DS/EN 196-1:2005 Methods of testing cement - Part 1: Determination of strength, 2005. 
DS/EN 196-5:2011 : Methods of testing cement - Part 5: Pozzolanicity test for pozzolanic cement, 2011.

DS/EN 197-1:2012 : Cement - Part 1: Composition, specifications and conformity criteria for common cements, 2012.

DS/EN 772-4:1998 Methods of test for masonry units - Part 4: Determination of real and bulk density and of total and open porosity for natural stone and masonry units, 1998.

Dyer, T.D., Halliday, J.E., Dhir, R., 2001. Hydration reaction of sewage sludge ash for use as a cement component in concrete production, in: Recycling and Reuse of Sewage Sludge. Thomas Telford Publishing, pp. 226-238. https://doi.org/10.1680/raross.29927.0019

Etris, S., Lieb, K., Sisca, V., Moore, I., Batik, A., Auskern, A., Horn, W., 1973. Capillary Porosity in Hardened Cement Paste. J. Test. Eval. 1, 74. https://doi.org/10.1520/JTE11604J

Eurostat - Tables, Graphs and Maps Interface (TGM) table [WWW Document], 2015. URL

http://ec.europa.eu/eurostat/tgm/table.do?tab=table\&init=1\&language=en $\&$ pcode $=$ ten00030\&plugin $=1$ (accessed 2.20.17).

Frigione, G., Marra, S., 1976. Relationship between particle size distribution and compressive strength in portland cement. Cem. Concr. Res. 6, 113-127. https://doi.org/10.1016/0008-8846(76)90056-9

Glavind, M., Munch-Petersen, C., 2000. "Green" concrete in Denmark. Struct. Concr. 1.

Goldman, A., Bentur, A., 1994. Properties of cementitious systems containing silica fume or nonreactive microfillers. Adv. Cem. Based Mater. 1, 209-215. https://doi.org/10.1016/1065-7355(94)90026-4

Halliday, J.E., Jones, M.R., Dyer, T.D., Ravindra K. Dhir, 2012. Potential use of UK sewage sludge ash in cement-based concrete. Proc. Inst. Civ. Eng. Waste Resour. Manag. 165, 57-66. https://doi.org/10.1680/warm.10.00039

Hemalatha, T., Ramaswamy, A., 2017. A review on fly ash characteristics- Towards promoting high volume utilization in developing sustainable concrete. J. Clean. Prod. https://doi.org/10.1016/j.jclepro.2017.01.114

Hewlett, P., 2004. Lea's Chemistry of Cement and Concrete, Fourth Edition, 4 edition. ed. Butterworth-Heinemann, Oxford; MA.

$\mathrm{Hu}, \mathrm{J}$., Ge, Z., Wang, K., 2014. Influence of cement fineness and water-to-cement ratio on mortar early-age heat of hydration and set times. Constr. Build. Mater. 50, 657-663. https://doi.org/10.1016/j.conbuildmat.2013.10.011

ISO 12571:2000 Hygrothermal performance of building materials and products Determination of hygroscopic sorption properties, n.d.

ISO 15148:2002 Hygrothermal performance of building materials and products Determination of water absorption coefficient by partial immersion, n.d.

Jamshidi, M., Jamshidi, A., Mehrdadi, N., Pacheco-Torgal, F., 2012. Mechanical performance and capillary water absorption of sewage sludge ash concrete (SSAC). Int. J. Sustain. Eng. 5, 228-234. https://doi.org/10.1080/19397038.2011.642020 
Kappel, A., Ottosen, L.M., Kirkelund, G.M., 2017. Colour, compressive strength and workability of mortars with an iron rich sewage sludge ash. Constr. Build. Mater. 157, 1199-1205. https://doi.org/10.1016/j.conbuildmat.2017.09.157

Kappel, A., Viader, R.P., Kowalski, K.P., Kirkelund, G.M., Ottosen, L.M., 2018. Utilisation of Electrodialytically Treated Sewage Sludge Ash in Mortar. Waste Biomass Valorization. https://doi.org/10.1007/s12649-018-0215-Z

Kute, S., Deodhar, S.V., 2003. Effect of fly ash and temperature on properties of burnt clay bricks. J. Inst. Eng. India Civ. Eng. Div. 84, 82-85.

Lambert, F., 2016. 6 major countries have recently announced imminent phase-out of all coal-fired power plants. Electrek.

Lawrence, C.D., 1998. 8 - Physicochemical and Mechanical Properties of Portland Cements, in: Hewlett, P.C. (Ed.), Lea's Chemistry of Cement and Concrete (Fourth Edition). Butterworth-Heinemann, Oxford, pp. 343-419. https://doi.org/10.1016/B978-075066256-7/50020-5

Lawrence, P., Cyr, M., Ringot, E., 2003. Mineral admixtures in mortars: Effect of inert materials on short-term hydration. Cem. Concr. Res. 33, 1939-1947. https://doi.org/10.1016/S0008-8846(03)00183-2

Lin, K.L., Chiang, K.Y., Lin, C.Y., 2005. Hydration characteristics of waste sludge ash that is reused in eco-cement clinkers. Cem. Concr. Res. 35, 1074-1081. https://doi.org/10.1016/j.cemconres.2004.11.014

Lin, K.-L., Lin, D.F., Luo, H.L., 2009. Influence of phosphate of the waste sludge on the hydration characteristics of eco-cement. J. Hazard. Mater. 168, 1105-1110. https://doi.org/10.1016/j.jhazmat.2009.02.149

Lynn, C.J., Dhir, R.K., Ghataora, G.S., West, R.P., 2015. Sewage sludge ash characteristics and potential for use in concrete. Constr. Build. Mater. 98, 767779. https://doi.org/10.1016/j.conbuildmat.2015.08.122

Malhotra, V.M., Mehta, P.K., 1996. Pozzolanic and Cementitious Materials. Taylor \& Francis.

Monzó, J., Payá, J., Borrachero, M.V., Córcoles, A., 1996. Use of sewage sludge ash(SSA)-cement admixtures in mortars. Cem. Concr. Res. 26, 1389-1398. https://doi.org/10.1016/0008-8846(96)00119-6

Monzó, J., Payá, J., Borrachero, M.V., Girbés, I., 2003. Reuse of sewage sludge ashes (SSA) in cement mixtures: the effect of SSA on the workability of cement mortars. Waste Manag. 23, 373-381. https://doi.org/10.1016/S0956053X(03)00034-5

Murakami, T., Suzuki, Y., Nagasawa, H., Yamamoto, T., Koseki, T., Hirose, H., Okamoto, S., 2009. Combustion characteristics of sewage sludge in an incineration plant for energy recovery. Fuel Process. Technol. 90, 778-783. https://doi.org/10.1016/j.fuproc.2009.03.003

Naamane, S., Rais, Z., Taleb, M., 2016. The effectiveness of the incineration of sewage sludge on the evolution of physicochemical and mechanical properties of Portland cement. Constr. Build. Mater. 112, 783-789. https://doi.org/10.1016/j.conbuildmat.2016.02.121

Nielsen, A., 1985. Betonbogen. Cementfabrikkernes tekniske Oplysningskontor,.

Nilsson, L.-O., 1980. Hygroscopic moisture in concrete - drying, measurements \& related material properties. Rep. TVBM 1003. 
Nurse, R.W., 1952. The effect of phosphate on the constitution and hardening of portland cement. J. Appl. Chem. 2, 708-716. https://doi.org/10.1002/jctb.5010021208

Ottosen, L.M., Jensen, P.E., Goltermann, P., Kirkelund, G.M., 2013. Sewage sludge ash as cement replacement after simple pretreatment, in: Proceedings of 14th International Waste Management and Landfill Symposium. Sardinia.

Pan, S.-C., Tseng, D.-H., Lee, C.-C., Lee, C., 2003a. Influence of the fineness of sewage sludge ash on the mortar properties. Cem. Concr. Res. 33, 1749-1754. https://doi.org/10.1016/S0008-8846(03)00165-0

Pan, S.-C., Tseng, D.-H., Lee, C.-C., Lee, C., 2003b. Influence of the fineness of sewage sludge ash on the mortar properties. Cem. Concr. Res. 33, 1749-1754. https://doi.org/10.1016/S0008-8846(03)00165-0

Patel, R.G., Killoh, D.C., Parrott, L.J., Gutteridge, W.A., 1988. Influence of curing at different relative humidities upon compound reactions and porosity in Portland cement paste. Mater. Struct. 21, 192-197. https://doi.org/10.1007/BF02473055

Piasta, W., Lukawska, M., 2016. The Effect of Sewage Sludge Ash on Properties of Cement Composites. Procedia Eng., World Multidisciplinary Civil EngineeringArchitecture-Urban Planning Symposium 2016, WMCAUS 2016 161, 10181024. https://doi.org/10.1016/j.proeng.2016.08.842

Powers, T.C., 1948. A discussion of cement hydration in relation to the curing of concrete. Portland Cement Association, Chicago.

Rößler, M., Odler, I., 1985. Investigations on the relationship between porosity, structure and strength of hydrated portland cement pastes I. Effect of porosity. Cem. Concr. Res. 15, 320-330. https://doi.org/10.1016/0008-8846(85)90044-4

Sedgwick, J., 1991. Strong but sensitive. Atl. Mon. 70-82.

Shen, W., Liu, Y., Yan, B., Wang, J., He, P., Zhou, C., Huo, X., Zhang, W., Xu, G., Ding, Q., 2017. Cement industry of China: Driving force, environment impact and sustainable development. Renew. Sustain. Energy Rev. 75, 618-628. https://doi.org/10.1016/j.rser.2016.11.033

Smol, M., Kulczycka, J., Henclik, A., Gorazda, K., Wzorek, Z., 2015. The possible use of sewage sludge ash (SSA) in the construction industry as a way towards a circular economy. J. Clean. Prod. 95, 45-54. https://doi.org/10.1016/j.jclepro.2015.02.051

Snellings, R., Mertens, G., Elsen, J., 2012. Supplementary Cementitious Materials. Rev. Mineral. Geochem. 74, 211-278. https://doi.org/10.2138/rmg.2012.74.6

Vaughan, A., 2016. Britain's last coal power plants to close by 2025 . The Guardian.

Wang, K.-S., Chiou, I.-J., Chen, C.-H., Wang, D., 2005. Lightweight properties and pore structure of foamed material made from sewage sludge ash. Constr. Build. Mater. 19, 627-633. https://doi.org/10.1016/j.conbuildmat.2005.01.002

Wiebusch, B., Seyfried, C.F., 1997. Utilization of sewage sludge ashes in the brick and tile industry. Water Sci. Technol. 36, 251-258. https://doi.org/10.1016/S02731223(97)00688-4

Worrell, E., Lynn Price, Nathan Martin, Chris Hendriks, Meida, L.O., 2001. Carbon Dioxide Emissions from the Global Cement Industry. Annu. Rev. Energy Environ. 26, 303-329. https://doi.org/10.1146/annurev.energy.26.1.303

Wyrzykowski, M., Lura, P., 2016. Effect of relative humidity decrease due to selfdesiccation on the hydration kinetics of cement. Cem. Concr. Res. 85, 75-81. https://doi.org/10.1016/j.cemconres.2016.04.003 
Yudenfreund, M., Hanna, K.M., Skalny, J., Older, I., Brunauer, S., 1972. Hardened Portland cement pastes of low porosity V. Compressive strength. Cem. Concr. Res. 2, 731-743. https://doi.org/10.1016/0008-8846(72)90008-7

Yusuf, R.O., Noor, Z.Z., Moh', N.A., Moh', d F., Din, d, Abba, A.H., 2012. Use of sewage sludge ash (SSA) in the production of cement and concrete - a review. Int. J. Glob. Environ. Issues 12, 214. https://doi.org/10.1504/IJGENVI.2012.049382

Zain, M.F.M., Islam, M.N., Mahmud, F., Jamil, M., 2011. Production of rice husk ash for use in concrete as a supplementary cementitious material. Constr. Build. Mater., Composite Materials and Adhesive Bonding Technology 25, 798-805. https://doi.org/10.1016/j.conbuildmat.2010.07.003

Zhou, J., Ye, G., van Breugel, K., 2010. Characterization of pore structure in cementbased materials using pressurization-depressurization cycling mercury intrusion porosimetry (PDC-MIP). Cem. Concr. Res. 40, 1120-1128. https://doi.org/10.1016/j.cemconres.2010.02.011

Highlights:

- High content of $\mathrm{P}_{2} \mathrm{O}_{5}$ was detected in both SSAs

- SSAs contained larger and more irregular-shaped grains when compared to cement

- SSA content clearly increased mortar porosity and water absorption

- SSA content caused a significant decrease in 28-day compressive strength of mortar

- Differences of SSAs and cement absorption had limited effect on mortar adsorption 